\title{
Atención primaria, incapacidad laboral y nuevas tecnologías
}

\author{
Primary care, incapacity for work \\ and new technology
}

\author{
Fernando Álvarez-Blázquez Fernández \\ Subdirección General Coordinación de Unidades Médicas \\ Dirección General. Instituto Nacional de la Seguridad Social \\ Madrid. España \\ E-mail: Fernando.alvarez-blazquez@inss.seg-social.es
}

Si bien los conceptos de incapacidad temporal y permanente, no han sufrido grandes variaciones en los últimos años, su gestión sí ha vivido distintas modificaciones, en la medida en que han ido desarrollándose diferentes normas que les afectan de manera directa.

Desde la innovación que supusieron el real decreto 1300/95, de 21 de julio, por el que se desarrollan las competencias en materia de incapacidad permanente y posteriormente el Real Decreto 575/97, de 18 de Abril, que regula diversos aspectos de gestión y control de la incapacidad temporal, hasta las más recientes variaciones de las competencias que afectan a la incapacidad temporal como consecuencia de la modificación del artículo 128 del Texto Refundido de la Ley General de la Seguridad Social y la regulación en enfermedades profesionales.

Son muchas las circunstancias que concurren en la gestión de las prestaciones del sistema de seguridad social por lo que es fácil comprender que su gestión ha de ser siempre dinámica y estar presidida desde una perspectiva de sostenibilidad y de racionalización del gasto.

La diversidad de las prestaciones del sistema de seguridad social que pueden dar lugar a una intervención de distintas entidades son bien conocidas. En efecto, son variados los actores que intervienen en las diversas prestaciones: los Servicios Públicos de Salud de las diferentes Comunidades Autónomas, las Mutuas de Accidentes de Trabajo y Enfermedades Profesionales de la Seguridad Social, el Instituto Nacional de la Seguridad Social, el Instituto Social de la Marina,etc..

Dependiendo del origen de la prestación, de su contingencia, si es común o profesional, la capacidad de intervención de los diferentes responsables también es distinta.

Existen también variables que inciden de una manera determinante en razón de la entidad responsable de la gestión, de la asistencia y del pago de la prestación. Así podemos encontrarnos con diferentes situaciones como consecuencia de que los beneficiarios tengan su cobertura con el Instituto Nacional de la Seguridad Social, con las Mutuas de Accidentes de Trabajo y Enfermedades Profesionales de la Seguridad Social, con el Instituto Social de la Marina,con las Empresas Colaboradoras de la Seguridad Social, con la Mutualidad General de Funcionarios Civiles del Estado, etc.

Pero por encima de cualquier consideración, existe una zona común a todas estas prestaciones que no es otra que la enfermedad, entendida no sólo como la falta de salud, sino en el momento en que ésta impide la realización del trabajo habitual de una persona, bien sea con carácter temporal o bien sea definitivamente. Es ahí, en ese lugar común a las prestaciones, en dónde es imprescindible que los esfuerzos de todos los médicos de atención primaria, especialistas de medicina del trabajo, médicos inspectores, etc. encuentren un lugar común en el que las patologías y su relación con el trabajo sean analizadas en términos homogéneos para que el sistema de seguridad social sea aplicado bajo el más estricto principio de equidad.

En muy pocos años, hemos asistido a avances tecnológicos que han revolucionado nuestra cultura, nuestros hábitos de trabajo, nuestros niveles de información, etc., hasta el punto de alcanzar objetivos impensables hace bien poco. Así, en nuestro ámbito, la historia médica informatizada, la receta electrónica, 
la emisión electrónica de partes de baja, la comunicación informática entre los distintos niveles del sistema asistencial, etc., ha dado lugar al planteamiento de objetivos inimaginables hasta hace bien poco.

En el caso concreto del Instituto Nacional de la Seguridad Social, es importante reseñar el impulso informático, que ha permitido un gran avance en la evolución de la gestión de la incapacidad temporal y próximamente de la incapacidad permanente, gracias al desarrollo del aplicativo de trabajo informático de las unidades médicas "ATRIUM", el cual ofrece la disponibilidad de una herramienta que es una auténtica base de datos y termómetro diario de las bajas de incapacidad temporal en todo el país, en la medida en que recibe la información de todas las bajas laborales desde las distintas comunidades autónomas y facilita una gestión informatizada de las Unidades Médicas de la entidad. En el momento actual se encuentra en desarrollo un sistema que permitirá en el plazo de un año que ATRIUM se pueda conectar con todas las Mutuas de Accidentes de Trabajo y Enfermedades Profesionales de la Seguridad Social, de tal forma que la información de gestión y sanitaria pueda fluir con las máximas garantías de rapidez y seguridad.

Estas herramientas de trabajo no serían útiles si no se viesen acompañadas de un esfuerzo profesional de los médicos que trabajan en los distintos ámbitos de la valoración de la incapacidad. Es el caso del documento publicado recientemente por el Instituto Nacional de la Seguridad Social, sobre "Tiempos Estándar de Incapacidad Temporal" que, implantado a través de los Convenios que el INSS tienen suscritos con todas las Comunidades Autónomas, se ha constituido como un trabajo de general aplicación al seguimiento de los pacientes en baja, o cuando elaboramos los "Manuales de actuación para médicos del INSS" como documentos de consenso de medicina evaluadora, o cuando ponemos al servicio de los médicos una "Guía de valoración profesional" con el estudio de las cargas de trabajo de más de 150 profesiones.

Es imprescindible, en el momento actual, buscar nuevas fórmulas de gestión de la incapacidad temporal en las que las herramientas informáticas adquieran el papel potencial que tienen, tanto en lo que se refiere a la gestión como a la asistencia médica, sin olvidar que el objetivo fundamental ha de ser la salud del paciente y cuando esta falta y con ello sobreviene una incapacidad para trabajar, nuestra responsabilidad es la de hacer que ese tránsito tenga la mayor y mejor cobertura sanitaria y social.

Este es el reto que estamos asumiendo, pero ese objetivo requiere un esfuerzo en el que se coordinen las distintas administraciones y se diseñen herramientas que faciliten nuestro trabajo diario como es el caso de la publicación del trabajo de "Criterios de valoración de la incapacidad para médicos de atención primaria" que se acompaña a este número de "Medicina y Seguridad del trabajo". Creo que el esfuerzo ha merecido la pena y que esta publicación pasará a formar parte en poco tiempo de esas "herramientas" imprescindibles en la medicina de valoración. 